\title{
Capturing the impact of nanobubble liquid in enhancing the physical quality of ice cream
}

Norhafizah Mohamad Khaira, Nur Aliaa Abd Rahmana*, Azhari Samsu Baharuddina, Halimatun Saadiah Hafidb, Minato Wakisakab

${ }^{a}$ Department of Process and Food Engineering, Faculty of Engineering, Universiti Putra Malaysia, 43400, Serdang, Selangor, Malaysia

${ }^{b}$ Graduate School of Life Science and Systems Engineering, Kyushu Institute of Technology, 2-4 Hibikino, Wakamatsu-ku, Kitakyushu, 808-0196, Japan

\section{ARTICLE HISTORY}

Received: 26 March 2020

Received in revised form: 3 May 2020

Accepted: 7 May 2020

Available Online: 11 May 2020

\section{Keywords}

Nanobubbles

Ice cream

Air bubbles

Food structure

Dairy processing

\section{Abstract}

Nanobubbles are bubbles of nanometer to micrometer size and are dispersed in a liquid water. In recent years, nanobubbles technology has been used in an extensive range of application such as in drinking water, agriculture, fishery, wastewater treatment and food. In ice cream, air cells are important for the smooth texture of ice cream. In this study, the effects of using nanobubble liquid in ice cream was compared with the one using normal water. Samples were prepared and analysis was conducted to check the physical properties of ice cream. Based on the results obtained, the apparent viscosity of ice cream made using nanobubble liquid ( INBL $_{\mathrm{N}}$ and normal water ( $\mathrm{I}_{\mathrm{NW}}$ ) were $0.211 \mathrm{~Pa}$.s and $0.149 \mathrm{~Pa} . \mathrm{s}$, respectively. $\mathrm{I}_{\mathrm{NBL}}$ ice cream had higher density and firmness which were $0.77 \mathrm{~g} / \mathrm{mL}$ and 34.80 gram-force, respectively while $\mathrm{I}_{\mathrm{NM}}$ ice cream had slightly lower density and firmness which were $0.74 \mathrm{~g} / \mathrm{mL}$ and 29.93 gram-force, respectively. The overrun of $\mathrm{I}_{\mathrm{NBL}}$ ice cream was lower which was $46 \%$ while $\mathrm{I}_{\mathrm{NW}}$ ice cream was $54 \%$. For both $\mathrm{I}_{\mathrm{NW}}$ and $\mathrm{I}_{\mathrm{NBL}}$ ice creams, the fastest melting rate was recorded between 10 $30 \mathrm{~min}$ at the rate of $1.491 \mathrm{~g} / \mathrm{min}$ and $1.558 \mathrm{~g} / \mathrm{min}$, respectively. INBL ice cream held its body slightly longer and melted a bit later than $\mathrm{I}_{\mathrm{NW}}$ ice cream. As a conclusion, ice cream with lower overrun is denser and has rich texture. Smaller air bubbles are able to hold the ice cream body better than the ones with larger air bubbles. Nanobubble liquid ice cream has higher firmness value which indicates its ability to better retain its shape.

\section{Introduction}

Ice cream is one of the most popular desserts in the world and the global ice cream market is forecasted to grow at a compound annual growth rate (CAGR) of $4.9 \%$ from 2020 until 2025 (Mordor Intelligence, 2020). Today, ice cream is found in almost any restaurant, shop and stall; and is recognized globally as the perfect dessert with vanilla and chocolate ice cream remain the leading flavors with nearly $36 \%$ of the total market share (Konstantas et al., 2019). Generally, ice cream is a complex food that is sometimes called frozen aerated emulsion (oil in water) and consists of partially coalesced fat globules, air bubbles, ice crystals and unfrozen serum together with polysaccharides contents, mineral salts, proteins and water as the main ingredients.

Ice cream ingredients are the main factors that affect the development of the desired structure, texture, dryness, shape retention after freezing process, melting and smoothness after hardening, and palatability of the final ice cream (Akbari et al., 2019). Not only the ingredients, the processing steps involved in ice cream production i.e. critical pasteurization, homogenization, ageing, freezing and hardening processed have important factors in determining the quality of ice cream produced.

Milk fat is usually the determinant factor in ice cream texture. The reduction of fat may lead to textural defects such as iciness and coarseness; and significantly affects the resultant ice cream flavor i.e. ice cream becomes less creamy and has reduced richness (Mahdian \& Karazhian, 2013). There were various studies conducted on the effects of ice cream ingredients i.e. type of fat replacers on the physicochemical and sensory properties of ice cream. However, very few studies focused on the effects of aeration on the quality of ice cream.
Nowadays, the advancement of nanotechnology has led to the development of nanobubbles which are extremely small gas bubbles that provide superior aeration and have drawn a huge attention from various fields especially food industry (Soutter, 2013). The unique properties of nanobubbles with ultrafine sizes (less than $100 \mathrm{~nm}$ diameter) possess high specific surface area per volume ratio and high internal pressure that facilitate the mass transfer efficiency in the interphase between air and liquid. Nanobubble liquid is a potential driver in food processing as the gaseous bubbles played a significant role in stability, microstructure and functionality of many food products such as beverages (wine and beer), baked products (bread and pastry), dairy products (ice cream and cheese), chocolate and confectionery products (Phan et al., 2020).

The utilization of nanobubble liquid for the improvement of ice cream properties is a new and interesting field of research. Amamcharla et al. (2017) stated that the interaction of nanobubble liquid with dairy products containing charged particles like milk proteins is believed to assist the reduction of liquid viscosity and prevent the aggregation of proteins. In addition, incorporation of nanobubble liquid improves texture, flavor and sensory characteristics of food as it is known that particle with size of less than $10 \mu \mathrm{m}$ cannot be individually perceived; and the contained energy per unit volume of food will be reduced by the dispersion of air bubbles. Therefore, the addition of nanobubble can help to obtain a healthier product with less consumed calories (Phan et al., 2020). In ice cream manufacturing, freezing and crystallization are among the important processes that ensure the quality of final ice cream. Infusing nanobubble air creates high pressure which promotes ice nucleation, accelerates heat and mass transfer, and reducing the ice crystal shape resulting in shorter freezing time and simultaneously increase the freezing rate (Akdeniz \& Alkalin, 2019). 
Considering the limited available studies on the application of nanobubble liquid especially in ice cream making process, therefore, this study aimed to determine the effects of nanobubble liquid on the physical properties of liquid mix (density and viscosity) and ice cream (overrun, firmness and melting rate). The preliminary data obtained from this study provides the understanding on how the size of air bubbles affects the physical quality of ice cream.

\section{Materials and Methods}

\subsection{Ice cream ingredients}

The ice cream formulation was prepared and adjusted based on the formulation reported by Rahman et al. (2019) i.e. $60.9 \% \mathrm{w} / \mathrm{w}$ of water, $14.5 \% \mathrm{w} / \mathrm{w}$ of skimmed milk, $16.3 \% \mathrm{w} / \mathrm{w}$ of sugar, $3.6 \% \mathrm{w} / \mathrm{w}$ of whey powder, $3.6 \% \mathrm{w} / \mathrm{w}$ of creamer, 0.4 $\% \mathrm{w} / \mathrm{w}$ of emulsifier, $0.3 \mathrm{w} / \mathrm{w}$ of stabilizer, $0.4 \mathrm{w} / \mathrm{w}$ of vanilla flavoring. The samples were divided into two groups: recipe containing normal water ( $\mathrm{I}_{\mathrm{NW}}$ ) and recipe with nanobubble liquid ( $\mathrm{I}_{\mathrm{NBL}}$ ) for comparisons. The particle size of the nanobubble liquid (Mishima Kosan Co. Ltd, Japan) is in the range of $<200 \mathrm{~nm}$. All the ingredients were weighed and blended together into liquid mix (500 g) by using a commercial mixer (Model 5K5SS, KitchenAid, St Michigan, USA) for five minutes until apparently homogenous mixture were obtained.

\subsection{Ice cream preparation}

The ice cream mix sample was batch pasteurized at $80{ }^{\circ} \mathrm{C}$ for 15 seconds and later homogenized using a laboratory scale homogenizer (Success Technic Industries, Model WT500, Malaysia). During ageing process, the ice cream mixture was left chilled at $4{ }^{\circ} \mathrm{C}$ for 12 hours to allow the fat to cool down and crystallize, and for the proteins and polysaccharides to fully hydrate. Ice cream were then produced using a batch ice cream freezer (Breville, Model BC1600, Australia). The ice cream was filled into an air-tight container and hardened in deep-freezer at $-20{ }^{\circ} \mathrm{C}$ for 24 hours.

\subsection{Physical quality analysis of ice cream}

The density and apparent viscosity of liquid ice cream mix were measured. The density was determined by dividing the measured mass of liquid mix over its volume. The apparent viscosity measurement was performed using a dynamic rheometer (AR-G2, TA Instrument, Newcastle, USA) using cone plate configuration of $1^{\circ}$ and 60 -mm diameter. The sample was loaded on rheometer base plate and allowed to rest for 10 minutes to prevent the influence of structural modification during sample handling and loading. The shear rate for this sample was set from $0-300 \mathrm{~s}^{-1}$.

Ice cream was stored at $-20^{\circ} \mathrm{C}$ for at least 24 hours prior to the physicochemical properties analysis. Ice cream overrun was determined according to the method described by Marshall et al. (2003) by using the formula shown in Equation 1:

$$
\text { Overrun }(\%)=\frac{M_{1}-M_{2}}{M_{2}} \times 100
$$

where, $M_{1}$ - mass of the ice cream mixture (g), and $M_{2}$ - mass of the ice cream $(\mathrm{g})$.

Texture analyser (TA.XT Plus, Stable Micro System, England) was used for determining the firmness of the samples. The thickness of hard ice cream block was $5 \mathrm{~cm}$ and it was tested at $25^{\circ} \mathrm{C}$. For each sample, three measurements were carried out using a $45^{\circ}$ perspex cone probe. The penetration depth at the geometrical centre of the samples was $50 \mathrm{~mm}$ and the penetration speed was set at $2.0 \mathrm{~mm} . \mathrm{s}^{-1}$.

The melting rate analysis was conducted by taking a sample of $37 \pm 1 \mathrm{~g}$ ice cream that was hardened in the deep-freezer. The ice cream is then positioned on a $1 \mathrm{~mm}$ wire screen mesh, together with a beaker placed on an electronic balance (Figure 1). The ice cream was allowed to melt under controlled room temperature $\left(25^{\circ} \mathrm{C}\right)$. The time required for the dripping of the first drop of melted ice cream was recorded using a stopwatch. The mass of the material passed through the screen was recorded at 5 min time intervals for 45 minutes duration until the structure of the ice cream collapsed as can be seen in Figure 1 . The melting rate was determined as the slope of the graphs of the dripped portion as a function of time, and expressed in $\mathrm{g} / \mathrm{min}$. A uniform distribution of small ice crystals and air cells results in gradual melting, a phenomenon that can be attributed to a reduced rate of heat transfer, since the trapped air functions as thermal resistance layers (Muse \& Hartel, 2004).

\section{Results and Discussion}

\subsection{Density and apparent viscosity of liquid ice cream mix}

The density and apparent viscosity of the liquid ice cream mix are presented in Figure 2. The density of the INBL ice cream mix was $0.77 \mathrm{~g} / \mathrm{mL}$ which is slightly higher than $\mathrm{I}_{\mathrm{NW}}$ ice cream $\operatorname{mix}(0.74 \mathrm{~g} / \mathrm{mL})$.
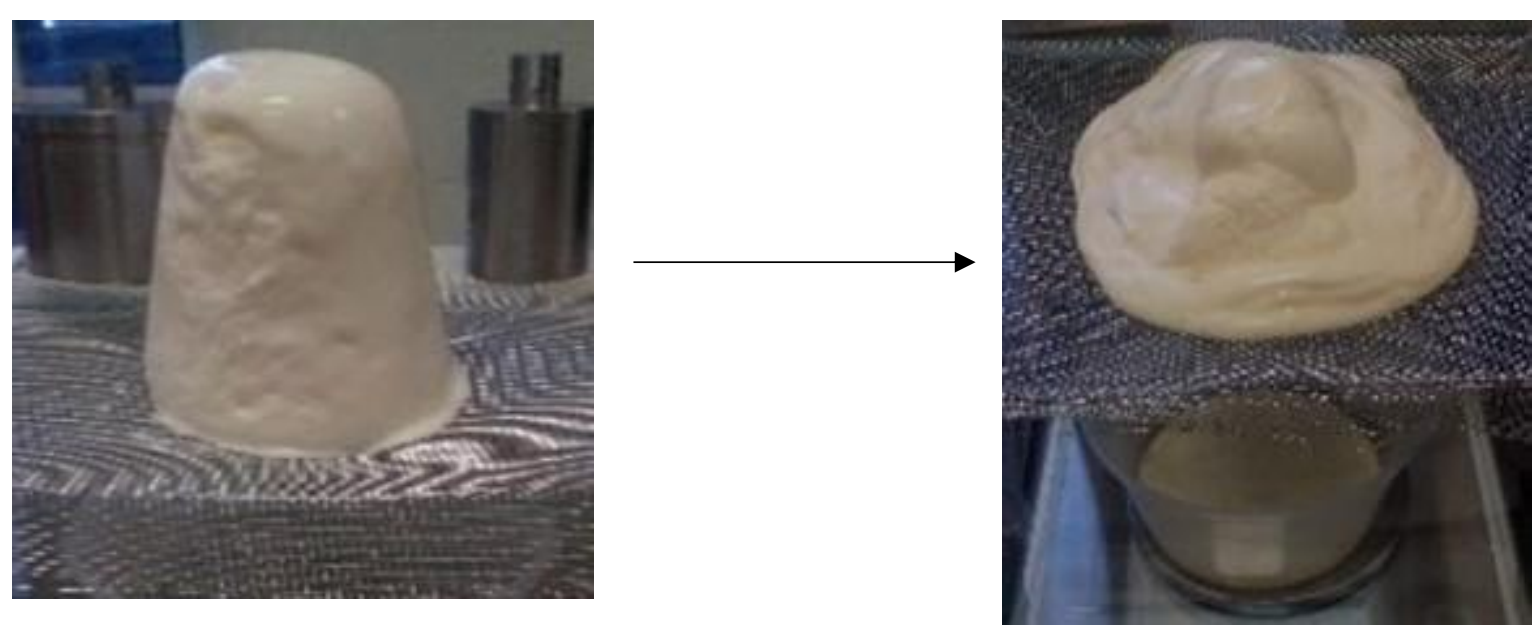

Figure 1. Experimental setup for melting rate analysis of hard ice cream 


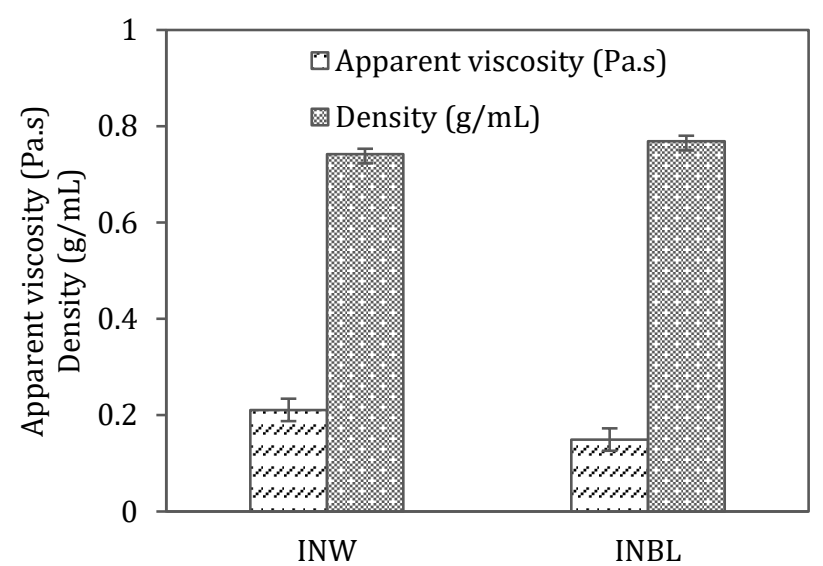

Figure 2. Density and apparent viscosity of ice cream made using normal water $\left(\mathrm{I}_{\mathrm{NW}}\right)$ and nanobubble liquid $\left(\mathrm{I}_{\mathrm{NBL}}\right)$

The apparent viscosity of ice cream made with nanobubble liquid, INBL (0.15 Pa.s) was approximately $30 \%$ lower than the one made using normal water, $\mathrm{I}_{\mathrm{NW}}(0.21 \mathrm{~Pa} . \mathrm{s})$. The presence of nanobubble liquid is believed to be the cause of decrease in the bulk viscosity of liquid mix. The reduction of the viscosity is due to the reaction that occurred when nanobubble water is in contact with the charged surface on the particles of milk protein and fat. In addition, the ultrafine nanobubbles plays a significant role as a buffer between milk protein particles which lead to their separation as well as preventing the aggregation of the proteins and fats (Amamcharla et al., 2017; Phan et al., 2020).

\subsection{Overrun and firmness of ice cream}

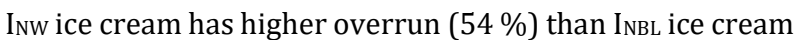
(46\%) as shown in Figure 3. Generally, the function of milk proteins in ice cream is to promote the formation of foam due to their amphiphilic characteristics thus, increase the volume and expansion of the ice cream (Durmaz et al., 2020). In this study, lower overrun of $\mathrm{I}_{\mathrm{NBL}}$ ice cream is attributed to the ultrafine size and slightly higher density of nanobubble liquid provide stability of the bubbles.

The amount of air incorporated into the ice cream mixture during the process was closely related to the firmness of the ice cream produced. An inverse relationship of the overrun and firmness was observed. Lower overrun led to denser ice cream with low flowability behavior observed, which indicates higher firmness of $I_{N B L}$ ice cream. Firmness is compared at the same distance of penetration. In this study, ice cream is penetrated by a probe to a distance of $\sim 50 \mathrm{~mm}$. The higher firmness $(34.8$ gram-force) of $\mathrm{I}_{\mathrm{NBL}}$ which was $16.4 \%$ higher than $\mathrm{I}_{\mathrm{NW}}$ ice cream indicated the ability of $\mathrm{I}_{\mathrm{NBL}}$ ice cream to retain its shape and texture better. Apart from overrun, firmness of ice cream is also affected by ice crystal size, ice phase volume, and the extent of fat destabilization. Ice cream with larger ice crystals is firmer compared to the one with small ice crystals (Goral et al., 2018).

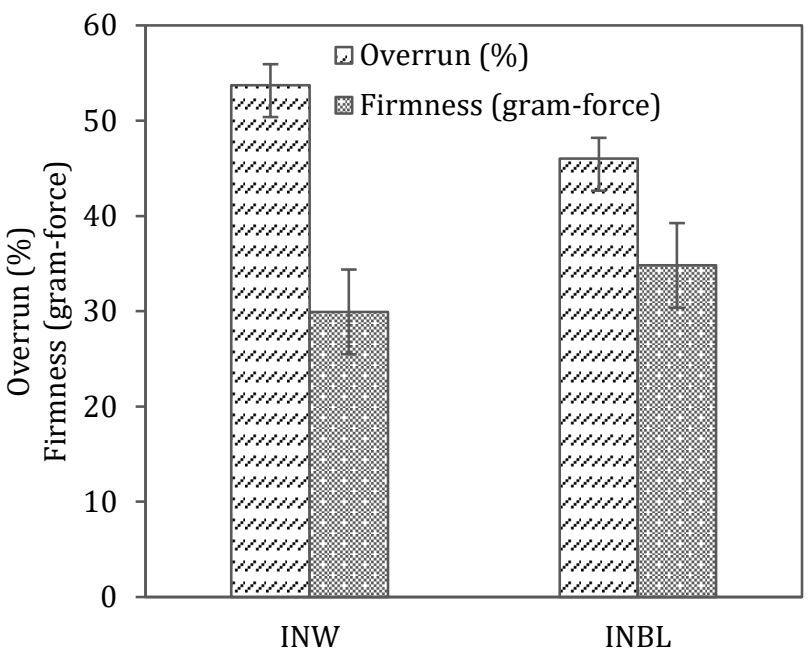

Figure 3. Overrun and firmness of ice cream made using normal water ( $\mathrm{INW}_{\mathrm{NW}}$ and nanobubble liquid ( $\left.\mathrm{I}_{\mathrm{NBL}}\right)$

\subsection{Melting rate of ice cream}

Melting behavior of ice cream is an important factor in assessing the quality, selection of technology and freezing parameter of ice cream. In addition, this criterion affected the shelf-life stability of the sample; as well as consumer perception such as mouthfeel and flavor release during sensory study. Effect of normal water and nanobubble liquid on the melting dynamics over time is presented in Figure 4. Nanobubble liquid addition did not remarkably influences the melting behavior

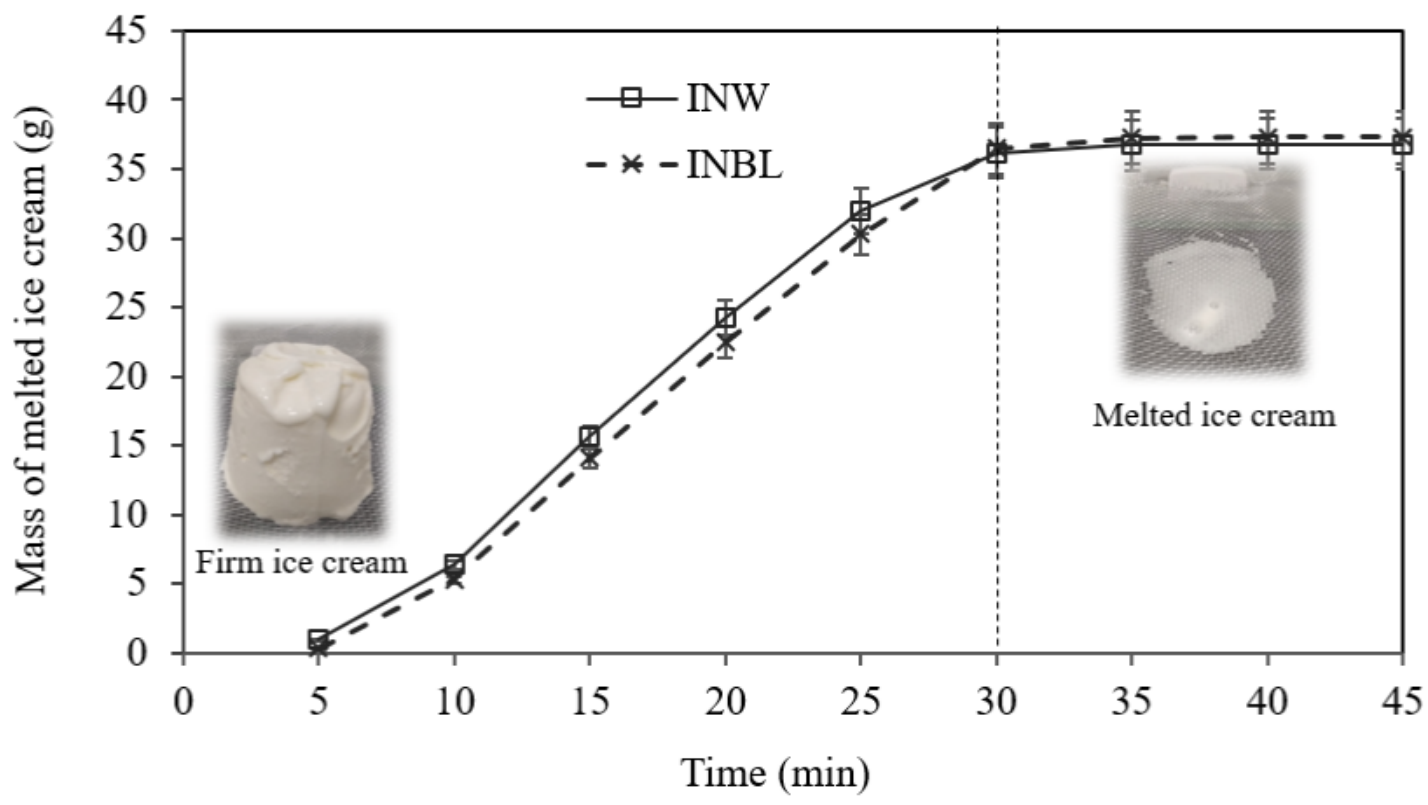

Figure 4. Melting curve of the ice cream produced using normal water, INW $(\square)$ and nanobubble liquid, $I_{N B L}(x)$ for 45 min test 
The INBL ice cream melts slightly later than the INw ice cream. The smaller air bubbles size holds the body better and causing the $I_{N B L}$ ice cream to melt a bit later than the ice cream produced using normal water. For both INw and INBL ice creams, the fastest melting rate was recorded between 10-30 $\mathrm{min}$ at the rate of $1.491 \mathrm{~g} / \mathrm{min}$ and $1.558 \mathrm{~g} / \mathrm{min}$, respectively. Lower viscosity of INBL liquid ice cream mix is the possible explanation of slightly faster melting rate of the $\mathrm{I}_{\mathrm{NBL}}$ ice cream compared to the $\mathrm{I}_{\mathrm{NW}}$ one. As melting process occurs, water (from melted ice) diffuses in the unfrozen fluid phase, flow downwards through the structural fat globules, milk proteins, ice crystal, air and polysaccharides sugar. Other ingredients incorporated in the ice cream act as resistance factor to fluid flow during the melting process (Lomolino et al., 2020).

\section{Conclusions}

The apparent viscosity and density of the INBL ice cream mix and the $\mathrm{I}_{\mathrm{NW}}$ ice cream mix are almost similar. The overrun of the $\mathrm{I}_{\mathrm{NBL}}$ sample (46\%) was slightly lower than the $\mathrm{I}_{\mathrm{NW}}$ one (54\%). This is due to the size of the air bubbles in INBL which affects the expansion of ice cream. Ice cream with lower overrun is denser and has rich texture. Smaller air bubble size holds the ice cream body better and causing the $\mathrm{I}_{\mathrm{NBL}}$ ice cream to melt a bit later than the ice cream produced using normal water, $\mathrm{I}_{\mathrm{NW}}$. $\mathrm{I}_{\mathrm{NBL}}$ ice cream has higher firmness value which indicates its ability to better retain its shape and possesses good texture. Physically, $\mathrm{I}_{\mathrm{NBL}}$ ice cream has comparable texture and look to the one produced using normal water, INw.

\section{Author contributions}

Norhafizah Mohamad Khair: conceptualization, methodology, data curation, and writing of the original draft. Nur Aliaa Abd Rahman: supervision, project administration, reviewing and editing of the final manuscript. Azhari Samsu Baharuddin: supervision and resources. Halimatun Saadiah Hafid: reviewing and editing of manuscript. Minato Wakisaka: resources.

\section{Conflict of interests}

The authors declare that they have no known competing financial interests or personal relationships that could have appeared to influence the work reported in this paper.

\section{Acknowledgements}

The authors would like to thank Kyushu Institute of Technology Educational Program 2017-2018 for the funding.

\section{References}

Akbari, M., Eskandari, M.H. \& Davoudi, Z. (2019). Application and functions of fat replacers in low-fat ice cream: A review. Trends in Food Science \& Technology, 86: 34-40. https://doi.org/10.1016/j.tifs.2019.02.036

Akdeniz, V. \& Akalin, A.S. (2019). New approach for yoghurt and ice cream production: High-intensity ultrasound. Trends in Food Science \& Technology, 86: 392-398. https://doi.org/10.1016/j.tifs.2019.02.046

Amamcharla, J., Li, B. \& Liu, Z. (2017). United States Patent: Use of micro and nanobubbles in liquid processing. WO 2017/127636 AI. PCT/US2017/014272

Durmaz, Y., Kilicli, M., Toker, O.S., Konar, N., Palabiyik, I. \& Tamtürk F. (2020). Using spray-dried microalgae in ice cream formulation as a natural colorant: Effect on physicochemical and functional properties. Algal
Research, 47: https://doi.org/10.1016/j.algal.2020.101811

101811.

Góral, M., Kozłowicz, K., Pankiewicz, U., Góral, D., Kluza, F. \& Wójtowicz A. (2018). Impact of stabilizers on the freezing process, and physicochemical and organoleptic properties of coconut milk-based ice cream. $L W T$ - Food Science and Technology, 92: 516-522. https://doi.org/10.1016/j.lwt.2018.03.010

Hansen, C.P. (2012). Stabilization of ice creams produced with a reduced level of saturated fat. Palsgaard Technical Paper, August 2012.

https://www.palsgaard.es/media/238438/stabilization $\% 20$ of\%20ice\%20cream\%20produced\%20with\%20re duced\%20level\%20of\%20saturated\%20fat.pdf

Konstantas, A., Stamford, L. \& Azapagic A. (2019). Environmental impacts of ice cream. Journal of Cleaner Production, 209: 259-272. https://doi.org/10.1016/j.jclepro.2018.10.237

Lomolino, G., Zannoni, S., Zabara, A., Lio, M.D. \& Iseppi A.D. (2020). Ice recrystallisation and melting in ice cream with different proteins levels and subjected to thermal fluctuation. International Dairy Journal, 100: 104557. https://doi.org/10.1016/j.idairyj.2019.104557

Mahdian, E. \& Karazhian R. (2013). Effects of fat replacers and stabilizers on rheological, physicochemical and sensory properties of reduced-fat Ice cream. Journal of Agricultural Science and Technology A, 15: 1163-1174. https://pdfs.semanticscholar.org/5a7f/1b3e3d427215 dd8693b0e20c8f6d88ee5dc2.pdf

Mordor Intelligence (2020). Ice cream market - growth, trends, and forecasts (2020 - 2025). https://www.mordorintelligence.com/industryreports/ice-cream-market

Muse, M. R. \& Hartel, R. W. (2004). Ice cream structural elements that affect melting rate and hardness. Journal of Dairy Sciences, 87: 1-10. https://doi.org/10.3168/jds.S00220302(04)73135-5

Phan, K.K.T., Truong, T., Wang, Y. \& Bhandari B. (2020). Nanobubbles: Fundamental characteristics and applications in food processing. Trends in Food Science \& Technology, 95: 118-130. https://doi.org/10.1016/j.tifs.2019.11.019

Rahman, N.A.A., Parid, D.M., Razak, S.Z.A, Johari, A.M., Talib, A.T., Mohammed, M.A.P., Baharuddin, A.S. \& Wakisaka, M. (2019). In-situ viscoelastic characterization and modeling of ice cream. Journal of Food Engineering, 263: 96-101. https://doi.org/10.1016/j.jfoodeng.2019.05.039

Soutter, W. (2013). What are Nanobubbles? https://www.azonano.com/article.aspx?ArticleID=3151 